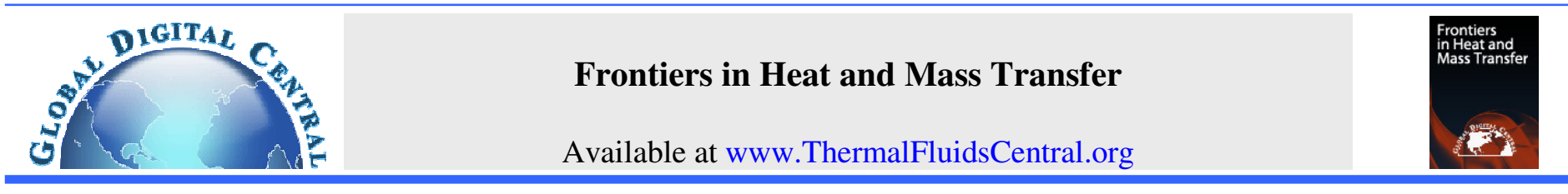

\title{
EFFECTIVE THERMAL RESISTANCE COMPARISON OF AEROGEL AND MULTI-LAYER INSULATION AS RADIATIVE BARRIERS USING THE SINGLE-SIDED GUARDED HOT PLATE METHOD
}

\author{
Kevin W. Irick* \\ Applied Technology Associates, Albuquerque, NM, 87123, USA
}

\begin{abstract}
The Single-sided Guarded Hot Plate Method for Comparative Testing of Thermal Radiation Barriers in Vacuum was used to evaluate the performance of a variety of aerogel insulation specimens manufactured by Aspen Aerogels $®$ against one another and against multi-layer insulation (MLI). Testing at the Air Force Research Laboratory (AFRL) shows that the effective thermal resistance, $R_{e}$, of all tested aerogel specimens are virtually bounded by the performance of 5-layer and 10-layer MLI specimens over a mean specimen temperature, $T_{m}$, range of about $270 \mathrm{~K}$ to $315 \mathrm{~K}$.

Keywords: aerogel, aerospace, material
\end{abstract}

\section{INTRODUCTION}

The Air Force Research Laboratory (AFRL) has developed an interest in robust aerospace systems. This interest has motivated the desire for a comparative analysis of next-generation thermal radiation insulatorsmore specifically, varieties of aerogel — with one another and with more traditional aerospace-applicable insulation, such as multi-layer insulation (MLI). Therefore, a tailored test method, referred to as the Single-sided Guarded Hot Plate Method for Comparative Testing of Thermal Radiation Barriers in Vacuum, has been developed at AFRL to perform such a comparative analysis. Using the developed method, a variety of aerogel specimens, manufactured by Aspen Aerogels®, have been tested. This paper briefly discusses the test method used and the experimental setup with emphasis on the comparative test results.

Despite the existence of complex test methods and standards for characterizing insulation, such as those proposed by ASTM C 177 (2013), ASTM C 1044 (1998), and ASTM C 1774 (2013), the proposed test method has been used as a simple, open-source means of evaluating radiative barriers in a vacuum environment. As opposed to absolute material property characterization, the results reported in this paper provide comparative insulation performance information using an effective thermal resistance, $R_{e}$, metric.

\section{BACKGROUND}

Traditionally, MLI has been used as insulation against radiative heat transfer in aerospace application for decades. MLI is comprised of a series of reflective foils to reduce overall transmission of radiating thermal energy and exists in an infinite number of configurations, depending on layer count, material thicknesses, fabrication processes, and reflector and spacer materials, such as Kapton, Mylar, Teflon, Dacron, and Nomex (Finckenor and Dooling, 1999). Despite its effective performance, MLI can incur significant costs in a flight project due to manufacturing, handling, and integration. By nature, MLI is a delicate insulation material, with performance highly sensitive to its physical condition. Wrinkles, holes, bends, and any other deformations in the blanket can take unpredictable and significant tolls on the overall performance of a given blanket. Therefore, any radiative barrier with insulative properties similar to or better than MLI - that also evades the manufacturing, handling, and integration pitfalls of MLI-would be considered a contender in insulation options.

Aerogel is an effective thermal conduction insulator, with thermal conductivity values ranging from $0.0007 \mathrm{~W} / \mathrm{m}-\mathrm{K}$ to $0.0089 \mathrm{~W} / \mathrm{m}-\mathrm{K}$, as reported to AFRL by Aspen Aerogels ${ }^{\circledR}$. The material itself is semirigid, much less delicate to handle in comparison to MLI, and is easy to integrate to a structure. Historically, aerogel has been used in a variety of applications such as in aerospace, aeronautical, metallurgical, structural, petroleum, refrigeration, energy, chemical, and biomedical fields (Aegerter et al., 2011). Specific to aerospace environments, the material has been used as a means of collecting orbital debris and space dust and thermally insulating spacecraft (Aegerter et al., 2011; Shang and Zhao, 2012). However, its evaluation in an open-source community as a radiative barrier in a vacuum environment is not readily available. In all logistical aspects, aerogel is considered a competitive alternative to MLI, and this motivates the comparative evaluation of aerogel as a radiative barrier against MLI.

\section{TEST METHOD}

The Single-sided Guarded Hot Plate Method for Comparative Testing of Thermal Radiation Barriers in Vacuum was used to compare seven insulation types. Essentially, the test method used employs an enclosed system as seen in Fig. 1.

The labeled portions of the apparatus are as follows:
1. Guarded Hot Plate (GHP)
2. Guarded Hot Plate Heater
3. G10 standoffs
4. Primary Guard (PG) Base
5. Primary Guard Cap 
6. Primary Guard Heaters

7. Insulation specimen

8. Cold Sink

9. Cold Plate

10. Screws

11. Secondary Guards (SG)

12. Washers

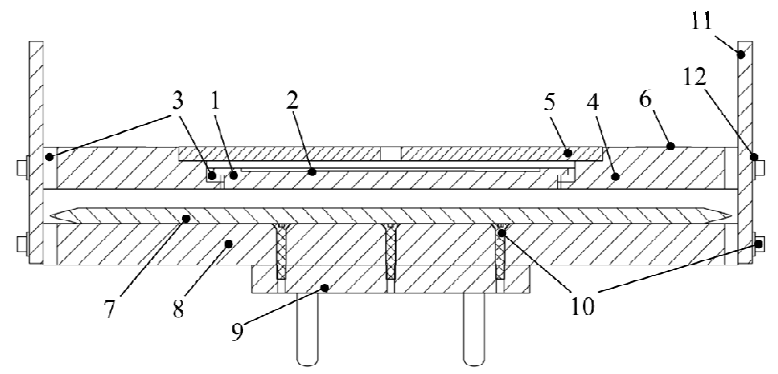

Fig. 1 Test apparatus cross-section

The PG prevents heat loss from the GHP, such that the heat applied to the GHP from the GHP heater flows through a given insulation specimen and into the cold plate. A detailed description of the test method used is given by Irick and Hengeveld (2016), which is dedicated to the theory and functionality of this test method.

The figure of merit used to compare specimens is $R_{e}$, described by

$$
R_{e}=(W B T-C B T) / Q_{G H P},
$$

where WBT and $C B T$ are the Warm Boundary Temperature and Cold Boundary Temperature, respectively, and $Q_{G H P}$ is the heat load applied to the GHP. The WBT is measured on the surface of the GHP facing the insulation specimen, and the $C B T$ is measured on the cold side of the insulation specimen (facing the cold sink).

\section{TEST SETUP}

The employed test method compares relative $R_{e}$ values of two or more insulation specimens. In this analysis, seven varieties of insulation were tested, as detailed in the following table.

Table 1 Insulation specimen types

\begin{tabular}{|c|c|c|}
\hline No. & Layup* & Makeup** \\
\hline 1 & 5-L MLI & 20-mil AlK/3x 1/4-mil AlM2p/5-mil AlK2p \\
\hline 2 & 8-L MLI & 2-mil AlK1p/6x 1/4-mil AlM2p/1-mil AlK2p \\
\hline 3 & 10-L MLI & 20-mil AlK/8x 1/2-mil AlM2p/20-mil AlK2p \\
\hline 4 & HT G2 A & 1/2-mil PAlK/1-mil AlM/AG2/1-mil AlM/1/2-mil AlK \\
\hline 5 & US G2 A & $1 / 2$-mil PAlK/5 $\mu \mathrm{m} \mathrm{fm} / \mathrm{AG} 2 / 5 \mu \mathrm{m} \mathrm{fm} / 1$-mil AlM \\
\hline 6 & MLAI W A & $\begin{array}{l}\text { 1/2-mil PAlK/5 } \mu \mathrm{m} \mathrm{fm} / \mathrm{AW} / 1 / 4-\mathrm{mil} \mathrm{PAlM} / \mathrm{AW} / 1 / 4-\mathrm{mil} \\
\mathrm{PAlM} / \mathrm{AW} / 5 \mu \mathrm{m} \mathrm{fm} / 1 \text {-mil AlM }\end{array}$ \\
\hline 7 & MLAI B A & $\begin{array}{l}\text { 1/2-mil PAlK/5 } \mu \mathrm{m} \mathrm{fm} / \mathrm{AB} / 1 / 4-\mathrm{mil} \mathrm{PAlM} / \mathrm{AB} / 1 / 4-\mathrm{mil} \\
\mathrm{PAlM} / \mathrm{AB} / 5 \mu \mathrm{m} \mathrm{fm} / 1 \text {-mil AlM }\end{array}$ \\
\hline \multicolumn{3}{|c|}{$\begin{array}{l}* \text { \#- } L=\text { no. of layers; } M L I=\text { Multi-layer Insulation; } H T=\text { Hand-taped; } \\
\text { US=Ultrasonically-sealed } ; M L A I=\text { Multi-layer Aerogel Insulation; } G 2=\text { Gen } 2 ; \\
A=\text { Aerogel } ; W=\text { White } ; B=\text { Black }\end{array}$} \\
\hline $\begin{array}{r}* * A l \\
P\end{array}$ & $=$ Aluminize & $\begin{array}{l}K=\text { Kapton } ; M=\text { Mylar } ; \# p=n o . \text { of perforated sides } \\
=\text { filter } \text { mesh } ; A=\text { Aerogel } ; W=\text { White } ; B=\text { Black }\end{array}$ \\
\hline
\end{tabular}

As described in Single-sided Guarded Hot Plate Method for Comparative Testing of Thermal Radiation Barriers in Vacuum (Irick and Hengeveld, 2016), the tests were performed in a controlled system. The test involves independent control of two sets of heaters as well as cold boundary temperature control using a recirculating chiller. The flowchart shown in Fig. 2 describes the test setup.

The test apparatus was designed for minimal handling during the interchange of specimens, where a single panel of the SG could be removed to allow for quick and simple installation and removal of the specimen. In order to control the GHP and PG temperatures, thin film heaters were positioned on the apparatus as seen in Fig. 3.

Temperature sensors located throughout the apparatus helped to control and monitor boundary temperatures and determine steady-state conditions. Sensors placed on the specimens were used to monitor boundary temperatures and find the mean specimen temperature. Figure 4 shows the location of temperature sensors on the specimen (hot side and cold side sensors placed directly above and beneath one another), where the dashed line represents the meter area, the region of measurement as defined by Irick and Hengeveld (2016). Placement of sensors is driven by guidelines in ASTM C 177 (2013) and ASTM C 1774 (2013).

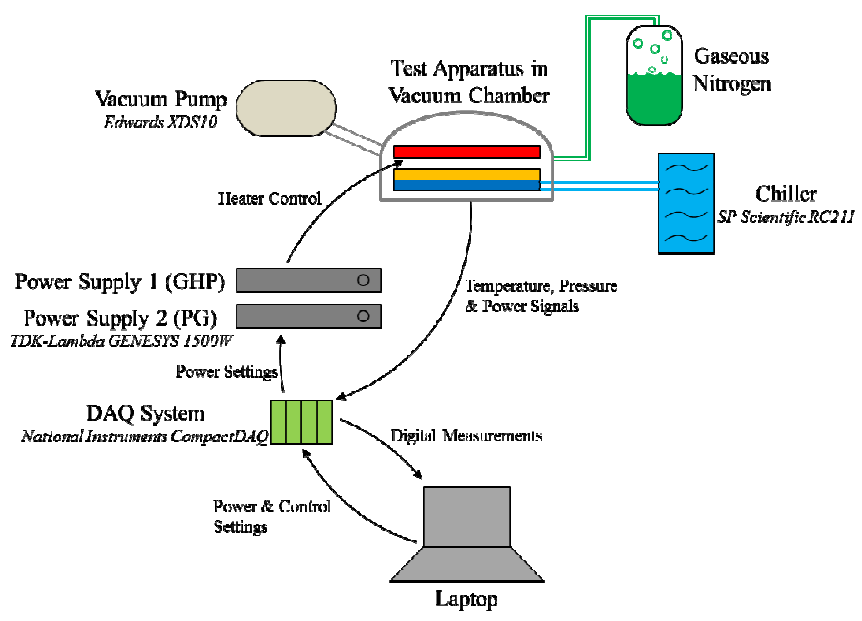

Fig. 2 Test setup flowchart

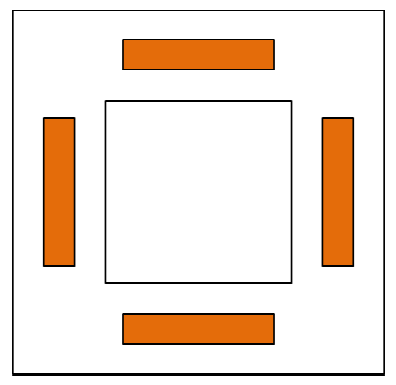

(a)

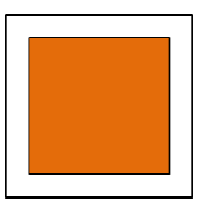

(b)
Fig. 3 Top view heater placement: a) Primary Guard, b) Guarded Hot Plate

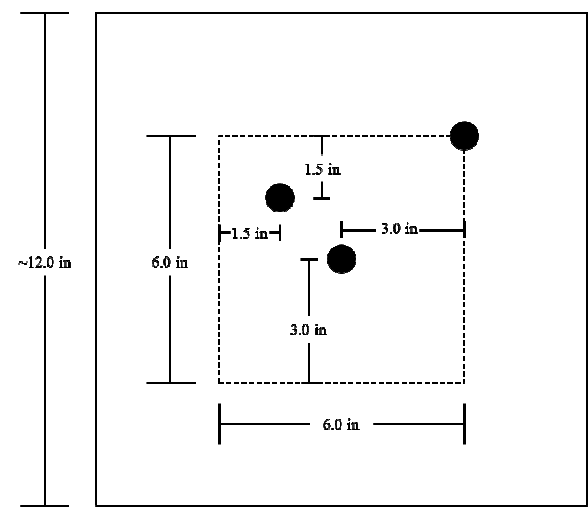

Fig. 4 Insulation specimen thermocouple placement 


\section{VALIDATION}

As a means of qualifying the test apparatus, a specimen of $6.35 \mathrm{~mm}$ ( 0.25 inch) thick G10 was covered on the hot side in aluminum tape and tested in the same manner as the aerogel and MLI specimens. From the test measurements, an approximate effective thermal conductivity, $k_{e f f}$, is backed out by

$$
k_{e f f}=Q_{G H P} \cdot t /\left[A_{m} \cdot\left(T_{h}-T_{c}\right)\right],
$$

where $t$ is the thickness of the specimen, $A_{m}$ is the meter area, and $T_{h}$ and $T_{c}$ are the hot and cold side specimen temperatures, respectively. In this set of tests, $T_{c}$ is the same as $C B T$.

The following table shows the resulting G10 effective thermal conductivity results from four temperature setpoints, where $T_{m}$ is the mean specimen temperature.

Table 2 G10 apparatus qualification results

\begin{tabular}{|c|c|}
\hline $\begin{array}{c}T_{m} \\
(\mathrm{~K})\end{array}$ & $\begin{array}{c}k_{\text {eff }} \\
(\mathrm{W} / \mathrm{m}-\mathrm{K})\end{array}$ \\
\hline $253.0 \pm 0.01$ & $0.405 \pm 0.006$ \\
\hline $254.9 \pm 0.01$ & $0.394 \pm 0.003$ \\
\hline $256.2 \pm 0.01$ & $0.396 \pm 0.002$ \\
\hline $256.6 \pm 0.01$ & $0.377 \pm 0.001$ \\
\hline
\end{tabular}

A generic reported thermal conductivity value range for commercial G10 is anywhere from $0.288 \mathrm{~W} / \mathrm{m}-\mathrm{K}$ (Boedeker, 2016) to $0.515 \mathrm{~W} / \mathrm{m}-\mathrm{K}$ (NIST, 2016). In-house verification testing of the covered G10 specimen showed a thermal conductivity value of approximately 0.457 $\pm 0.094 \mathrm{~W} / \mathrm{m}-\mathrm{K}$ at $294.8 \mathrm{~K}$. The average thermal conductivity as found using the radiative barrier test setup is $0.393 \mathrm{~W} / \mathrm{m}-\mathrm{K}$, deviating from its measured value by $14 \%$. Because neither the verification nor the guarded hot plate test was intended to provide absolute measurements of the thermal properties of the specimen, the results are reasonable and qualify the test apparatus for comparative testing of effective thermal resistance.

\section{RESULTS}

From the insulation types listed in Table 1, one specimen of each of the MLI varieties was tested, whereas three specimens of each aerogel variety were tested. Each specimen was tested at WBT setpoints of 25 , 50,75 , and $100^{\circ} \mathrm{C}$ with a constant approximate $C B T$ of $-20^{\circ} \mathrm{C}$. The system was run such that the necessary power was found for each specimen to achieve the specified WBT. Tables 3 through 7 show the test conditions of each test, where $S N$ is the serial number of a given specimen, $\varepsilon$ is the hot side specimen surface emissivity, and $C V P$ is the Cold Vacuum Pressure of a given test. Total uncertainty ranges for certain measured values are given in Appendix B.

Table 3 MLI test conditions

\begin{tabular}{|c|c|c|c|c|c|c|c|c|c|c|c|c|}
\hline$S N$ & \multicolumn{4}{|c|}{ 5L-MLI-001 } & \multicolumn{4}{|c|}{ 8L-MLI-001 } & \multicolumn{4}{|c|}{ 10-MLI-001 } \\
\hline$\varepsilon$ & & & & & & & & & & & & \\
\hline$C V P$ (torr) & $5.6 \mathrm{E}-03$ & $5.6 \mathrm{E}-03$ & $5.6 \mathrm{E}-03$ & $5.6 \mathrm{E}-03$ & $4.4 \mathrm{E}-03$ & $4.4 \mathrm{E}-03$ & $4.4 \mathrm{E}-03$ & $4.4 \mathrm{E}-03$ & $5.0 \mathrm{E}-03$ & $5.0 \mathrm{E}-03$ & $5.0 \mathrm{E}-03$ & $3.1 \mathrm{E}-03$ \\
\hline$W B T(\mathrm{~K})$ & 298.2 & 323.1 & 348.1 & 373.2 & 298.1 & 323.1 & 348.1 & 373.2 & 298.2 & 323.2 & 348.2 & 373.1 \\
\hline$C B T(\mathrm{~K})$ & 1.5 & 247.7 & 252.0 & 255.5 & 253.1 & 254.4 & 251.8 & 253.7 & 253.7 & 253.9 & 254.1 & 254.0 \\
\hline$Q_{G H P}(\mathrm{~W})$ & 0.264 & 0.553 & 1.077 & 1.993 & 0.122 & 0.229 & 0.383 & 0.648 & 0.108 & 0.247 & 0.460 & 0.637 \\
\hline
\end{tabular}

Table 4 Hand-taped Gen 2 Aerogel test conditions

\begin{tabular}{|c|c|c|c|c|c|c|c|c|c|c|c|c|}
\hline$S N$ & \multirow{2}{*}{\multicolumn{4}{|c|}{ HT-G2_-001 }} & \multicolumn{4}{|c|}{ HT-G2_-002 } & \multicolumn{4}{|c|}{ HT-G2_-003 } \\
\hline$\varepsilon$ & & & & & & 0. & & & & 0. & & \\
\hline$C V P$ (torr) & $3.5 \mathrm{E}-03$ & $3.5 \mathrm{E}-03$ & $3.5 \mathrm{E}-03$ & $3.8 \mathrm{E}-03$ & $3.5 \mathrm{E}-03$ & $3.5 \mathrm{E}-03$ & $3.5 \mathrm{E}-03$ & $3.5 \mathrm{E}-03$ & $3.5 \mathrm{E}-03$ & $3.5 \mathrm{E}-03$ & $3.5 \mathrm{E}-03$ & $3.5 \mathrm{E}-03$ \\
\hline$W B T(\mathrm{~K})$ & 298.1 & 323.2 & 348.2 & 373.2 & 298.2 & 323.1 & 348.2 & --- & 298.1 & 323.2 & 348.2 & 373.2 \\
\hline$C B T(\mathrm{~K})$ & 253.5 & 3.6 & 253.3 & 254.2 & 252.5 & 251.5 & 252.8 & --- & 252.9 & 253.4 & 253.8 & 251.4 \\
\hline$Q_{G H P}(\mathrm{~W})$ & 0.108 & 0.251 & 0.471 & 0.763 & 0.133 & 0.249 & 0.463 & --- & 0.126 & 0.244 & 0.412 & 0.641 \\
\hline
\end{tabular}

Table 5 Ultrasonically-sealed Gen 2 Aerogel test conditions

\begin{tabular}{|c|c|c|c|c|c|c|c|c|c|c|c|c|}
\hline$S N$ & \multicolumn{4}{|c|}{ US-G2_-001 } & \multicolumn{4}{|c|}{ US-G2_-002 } & \multicolumn{4}{|c|}{ US-G2_-003 } \\
\hline$\varepsilon$ & \multicolumn{4}{|c|}{0.052} & \multicolumn{4}{|c|}{0.045} & \multicolumn{4}{|c|}{0.049} \\
\hline$C V P$ (torr) & $3.6 \mathrm{E}-03$ & $3.6 \mathrm{E}-03$ & $3.6 \mathrm{E}-03$ & $3.2 \mathrm{E}-03$ & $3.5 \mathrm{E}-03$ & $4.2 \mathrm{E}-03$ & $4.2 \mathrm{E}-03$ & $4.2 \mathrm{E}-03$ & $4.4 \mathrm{E}-03$ & $4.4 \mathrm{E}-03$ & $4.4 \mathrm{E}-03$ & 4.4E-03 \\
\hline$W B T(\mathrm{~K})$ & 298.2 & 323.2 & 348.2 & 373.2 & 298.1 & 323.2 & 348.2 & 373.1 & 298.2 & 323.2 & 348.2 & 373.2 \\
\hline$C B T(\mathrm{~K})$ & 6 & 3.6 & 255.2 & 257.3 & 4.5 & 252.7 & 254.7 & 254.9 & 253.4 & 253.4 & 253.9 & 253.2 \\
\hline$Q_{G H P}(\mathrm{~W})$ & 0.221 & 0.422 & 0.732 & 1.146 & 0.205 & 0.436 & 0.764 & 1.154 & 0.211 & 0.410 & 0.699 & 1.072 \\
\hline
\end{tabular}

Table 6 Multi-layer Aerogel Insulation White test conditions

\begin{tabular}{|c|c|c|c|c|c|c|c|c|c|c|c|c|}
\hline$S N$ & \multicolumn{4}{|c|}{ MA-_W-001 } & \multicolumn{4}{c|}{ MA-_W-002 } & \multicolumn{4}{c|}{ MA-_W-003 } \\
\hline$\varepsilon$ & \multicolumn{4}{|c|}{0.530} & \multicolumn{3}{c|}{0.058} & \multicolumn{4}{c|}{0.061} \\
\hline$C V P($ torr $)$ & $3.7 \mathrm{E}-03$ & $3.7 \mathrm{E}-03$ & $3.1 \mathrm{E}-03$ & $3.1 \mathrm{E}-03$ & $4.4 \mathrm{E}-03$ & $3.2 \mathrm{E}-03$ & $3.2 \mathrm{E}-03$ & $3.2 \mathrm{E}-03$ & $3.8 \mathrm{E}-03$ & $3.8 \mathrm{E}-03$ & $3.8 \mathrm{E}-03$ & $3.8 \mathrm{E}-03$ \\
\hline$W B T(\mathrm{~K})$ & 298.2 & 323.2 & 348.2 & 373.1 & 298.1 & 323.1 & 348.2 & 373.1 & 298.0 & 323.2 & 348.2 & 373.2 \\
\hline$C B T(\mathrm{~K})$ & 252.3 & 252.4 & 249.6 & 250.8 & 251.4 & 252.3 & 252.5 & 252.4 & 251.8 & 251.8 & 252.1 & 252.0 \\
\hline$Q_{\text {GHP }}(\mathrm{W})$ & 0.140 & 0.273 & 0.424 & 0.660 & 0.123 & 0.192 & 0.418 & 0.908 & 0.116 & 0.238 & 0.381 & 0.614 \\
\hline
\end{tabular}

Table 7 Multi-layer Aerogel Insulation Black test conditions

\begin{tabular}{|c|c|c|c|c|c|c|c|c|c|c|c|c|}
\hline$S N$ & \multicolumn{4}{|c|}{ MA-_B-001 } & \multicolumn{4}{c|}{ MA-_B-002 } & \multicolumn{4}{c|}{ MA-_B-003 } \\
\hline$\varepsilon$ & \multicolumn{4}{|c|}{0.041} & \multicolumn{4}{c|}{0.054} & \multicolumn{5}{c|}{0.056} \\
\hline$C V P$ (torr) & $4.1 \mathrm{E}-03$ & $4.1 \mathrm{E}-03$ & $4.1 \mathrm{E}-03$ & $4.1 \mathrm{E}-03$ & $4.2 \mathrm{E}-03$ & $4.2 \mathrm{E}-03$ & $4.2 \mathrm{E}-03$ & $4.2 \mathrm{E}-03$ & --- & --- & --- & --- \\
\hline$W B T(\mathrm{~K})$ & 298.1 & 323.2 & 348.2 & 373.2 & --- & 323.2 & 348.2 & 373.2 & 298.0 & 322.8 & 348.2 & 373.1 \\
\hline$C B T(\mathrm{~K})$ & 250.8 & 252.0 & 252.4 & 251.2 & --- & 251.2 & 251.0 & 252.1 & 250.9 & 251.7 & 250.7 & 252.5 \\
\hline$Q_{G H P}(\mathrm{~W})$ & 0.082 & 0.217 & 0.383 & 0.658 & --- & 0.211 & 0.364 & 0.581 & 0.122 & 0.214 & 0.373 & 0.568 \\
\hline
\end{tabular}


Using the $C B T$ and the warm side specimen temperature to compute the mean specimen temperature, the charts shown in Fig. 5 display the effective thermal resistance performance of each aerogel specimen in relation to other aerogel specimens of the same type and to the MLI specimens.

For each insulation type, it can be shown that a function fit to approximate the resistive performance of each variety of insulation with respect to $T_{m}$ is of the form

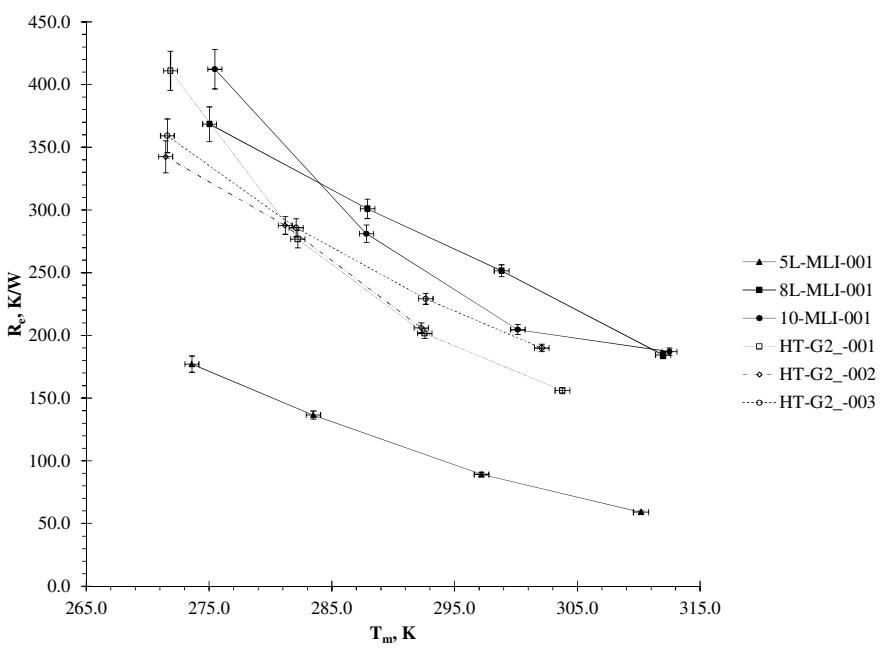

(a)

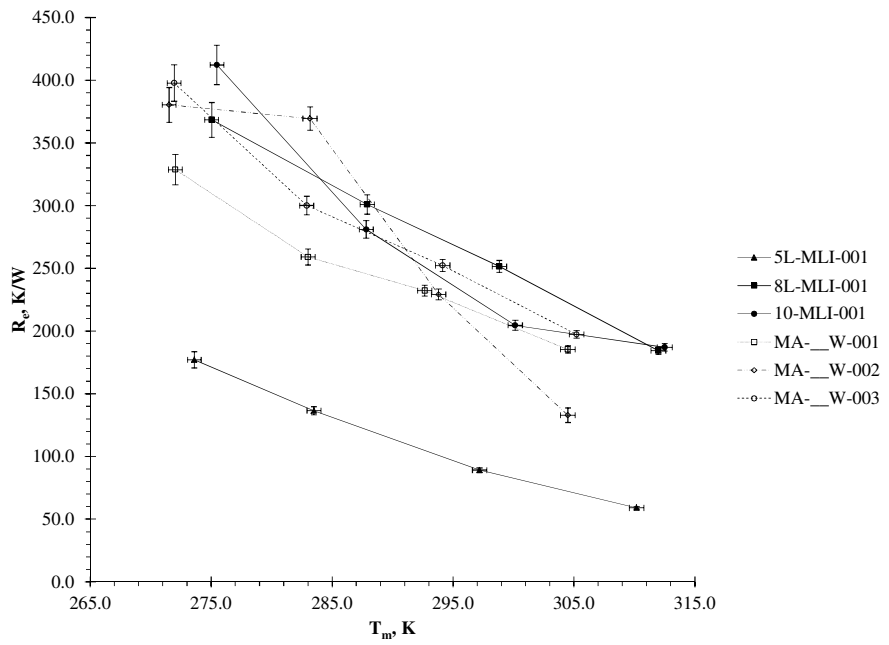

(c)
$R_{e}\left(T_{m}\right)=\left[\left(A \cdot\left[T_{m}-B\right]+\left[2 \cdot T_{m}-B\right]^{4}\right)^{0.25}-B\right] \cdot C /\left[T_{m}-B\right]$,

where $A, B$, and $C$ are constants for each unique function. Figure 6 shows the performance of each variety of insulation with respect to the mean specimen temperature.

The 8-layer and 10-layer MLI specimens perform similarly. It is likely that the performances of the specimens are similar, despite the difference in layer count, due to the individual makeup of each specimen.

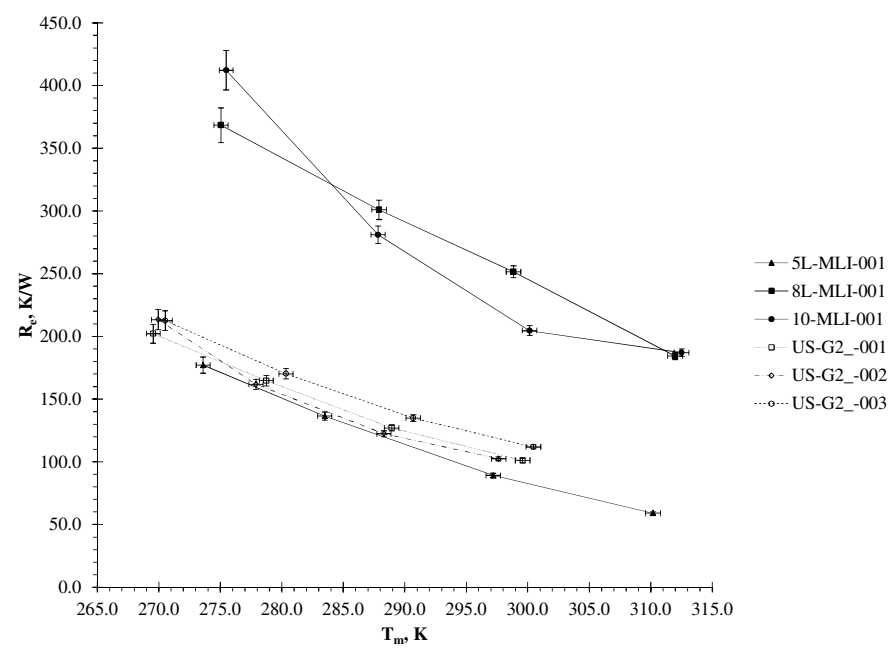

(b)

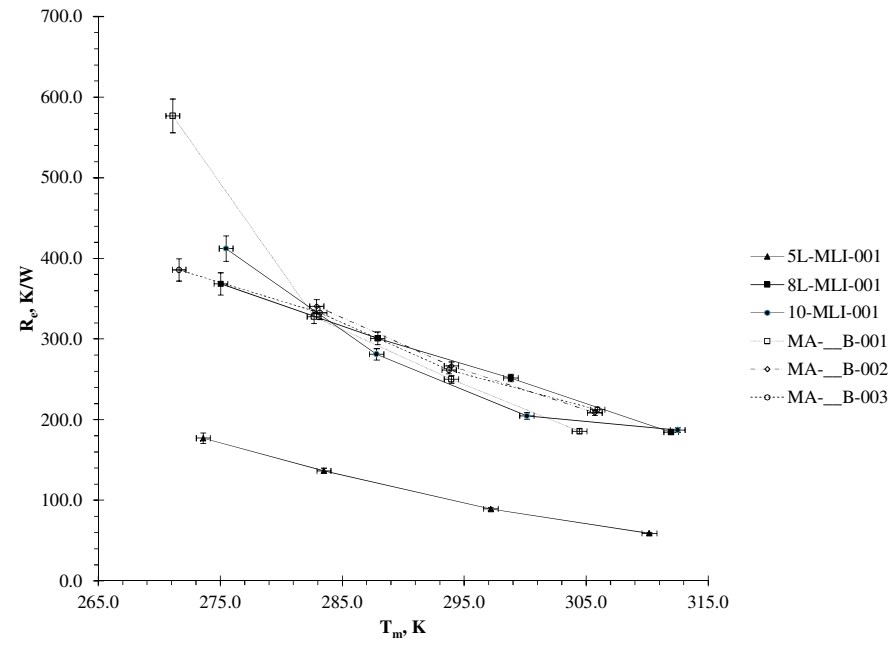

(d)

Fig. $5 R_{e}$ of aerogel specimens vs. MLI: a) Hand-taped Gen 2 Aerogel, b) Ultrasonically-sealed Gen 2 Aerogel, c) Multi-layer Aerogel Insulation White, d) Multi-layer Aerogel Insulation Black 


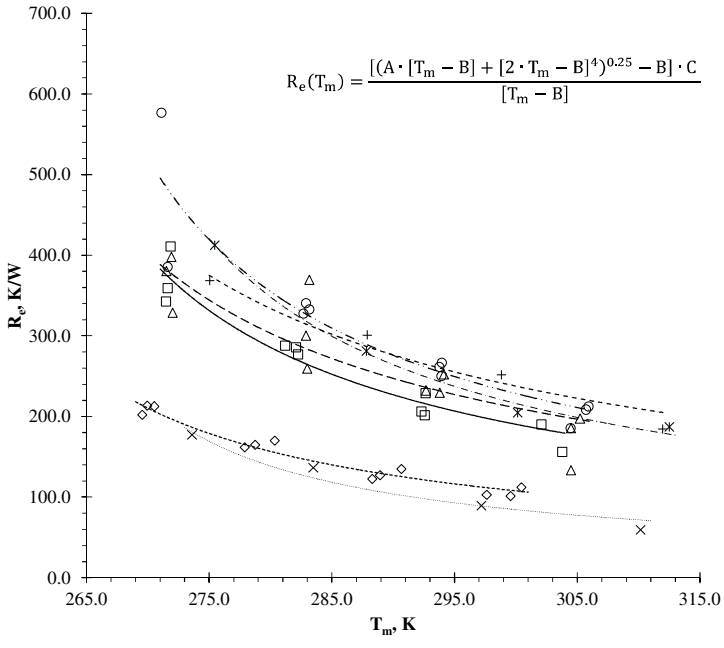

Fig. 6 Aggregate aerogel testing results

The disparate performance between the ultrasonically-sealed and hand-taped blankets is surprising, considering that the only fundamental difference between the specimens should be the method used to seal the specimen edges, shown in Fig. 7. The ultrasonically-sealed specimens perform with lower effective resistance than the hand-taped specimens which could be attributed to two causes:

1. Ultrasonically-sealed specimens show larger gaps between the warm boundary heat transfer surface and the specimen (see Appendix A) which would result in heat loss from the $G H P$ and, therefore, lower effective resistance.

2. Edge effects could be significantly prevalent. The ultrasonically-sealed seams are compressed as compared to the non-compressed edges of the hand-taped specimens, as seen in the following figure. Compression could decrease the overall resistance of the specimen.

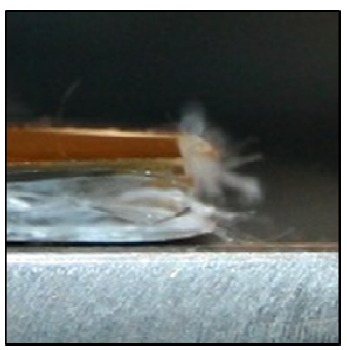

(a)

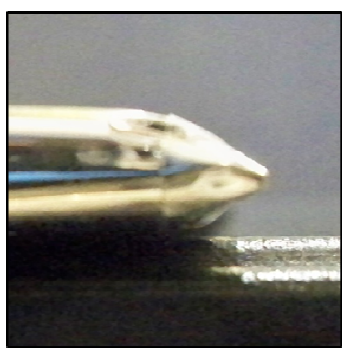

(c)

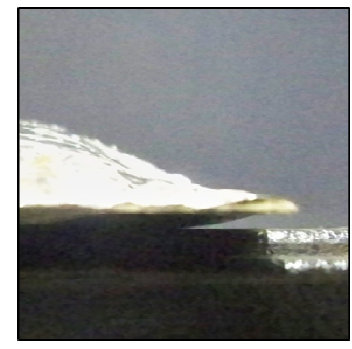

(b)

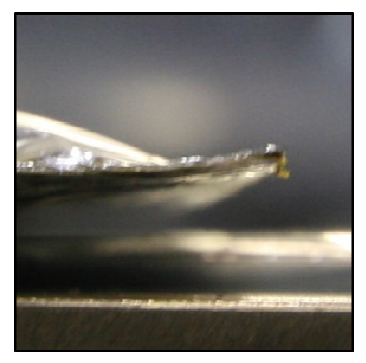

(d)
Fig. 7 Edge differences between specimens: a) MLI, b) Hand-taped, c) Ultrasonically-sealed, d) Multi-layer Aerogel Insulation

From the results, it is also possible to compute an effective thermal conductivity for each specimen, as was done for the G10 specimen during apparatus qualification. Figure 8 shows the effective thermal conductivity-as found through this comparative test-for each insulation type.

Another common performance metric for radiative barriers is the effective emittance value, $\varepsilon^{*}$ (Gilmore, 2002). Effective emittance is found by the following equation.

$\mathcal{E}^{*}=k_{e f f} \cdot\left(T_{h}-T_{c}\right) /\left[\sigma \cdot t \cdot\left(T_{h}^{4}-T_{c}^{4}\right)\right]$

Here, $\sigma$ represents the Stefan-Boltzmann constant, approximately evaluated at $5.67 \times 10^{-8} \mathrm{~W} / \mathrm{m}^{2}-\mathrm{K}^{4}$. Figure 9 displays computed $\varepsilon^{*}$ values for each insulation type.

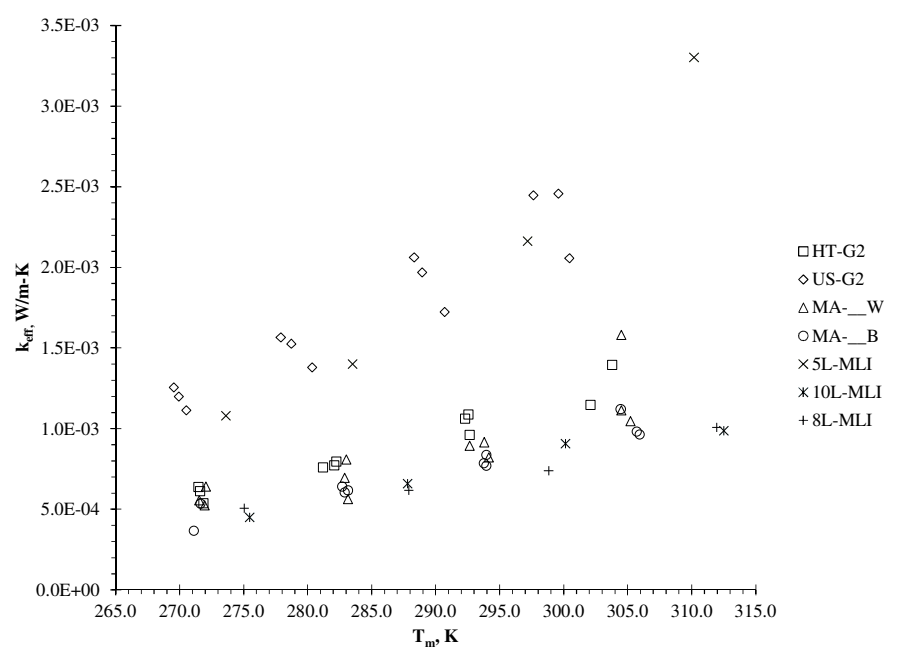

Fig. 8 Effective thermal conductivity of specimens

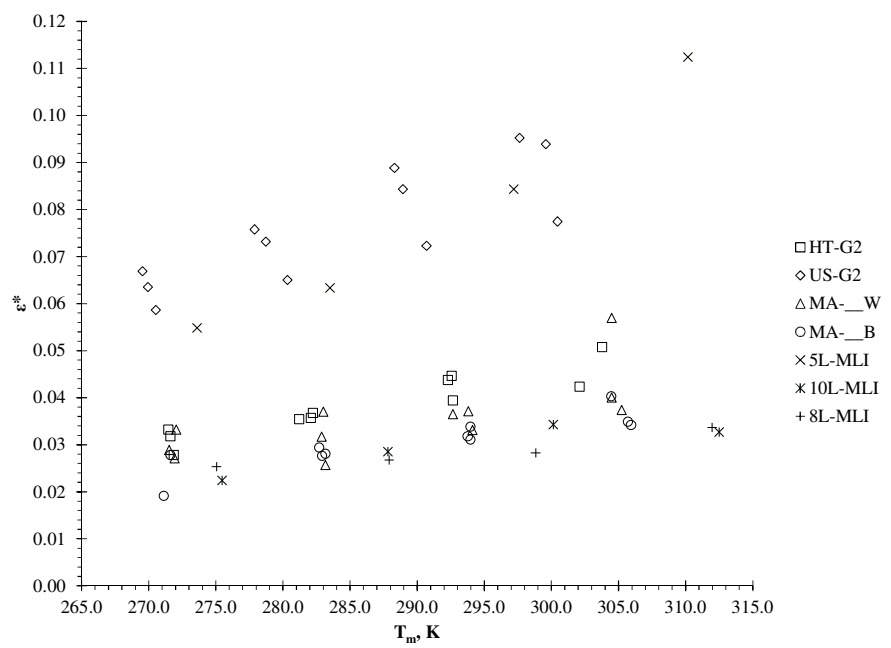

Fig. 9 Effective emittance of specimens

When compared to effective emittance values for MLI as published in the Spacecraft Thermal Control Handbook, the resultant values from this test tend to be higher yet fall within a reasonable margin from those already published. It is explained that for a given radiative barrier specimen, the effective emittance value tends to increase with decreased specimen size and increase with a reduction in number of layers (Gilmore, 2002). The meter areas of the specimens tested at AFRL are considerably small at approximately $0.023 \mathrm{~m}^{2}$, with a maximum of 10 layers.

It is important to note the lack of error bars and/or uncertainty given in the results of effective thermal conductivity and effective emittance. Because this test does not intend to or claim to provide absolute measurements for these two characterizing values, uncertainty 
for these calculations is not deemed appropriate. Rather, the metrics are shown for comparative value only.

\section{CONCLUSIONS AND PATH FORWARD}

This set of comparative tests suggests that from the aerogel varieties tested, Aspen Aerogels ${ }^{\circledR}$ aerogel insulation blankets are comparable substitutes to traditional MLI blankets (ranging from 5-layer to 10layer). Additional statistical data is needed to more reliably verify performance attributes of aerogel versus MLI, but the results of this test show promise in a competitive form of thermal radiation insulation. It is advisable that the gap distance in such tests as this be controlled with as much precision and accuracy as is possible. In this comparison, the surface emissivities of the MLI specimens were an order of magnitude greater than those of the aerogel specimens, thus it would be advisable to consider variation in MLI makeup and surface properties to perform a thorough trade study of the insulation types.

\section{ACKNOWLEDGEMENTS}

Thanks to Aspen Aerogels $\AA$, who manufactured the many aerogel insulation specimens used in this test under Air Force Research Laboratory Space Vehicles Directorate contract FA9453-09-C-0359. Comparative insulation testing was completed under Air Force Research Laboratory Space Vehicles Directorate contract FA9453-14D-0312.

\section{NOMENCLATURE}

$\begin{array}{ll}A & \text { function constant } \\ A_{m} & \text { meter area }\left(\mathrm{m}^{2}\right) \\ B & \text { function constant } \\ C & \text { function constant } \\ C B T & \text { cold boundary temperature }(\mathrm{K}) \\ C V P & \text { cold vacuum pressure (torr) } \\ k_{e f f} & \text { effective thermal conductivity }(\mathrm{W} / \mathrm{m}-\mathrm{K}) \\ Q_{G H P} & \text { heat load to Guarded Hot Plate }(\mathrm{W}) \\ R_{e} & \text { effective thermal resistance }(\mathrm{K} / \mathrm{W}) \\ t & \text { thickness }(\mathrm{m}) \\ T_{c} & \text { specimen cold side temperature }(\mathrm{K}) \\ T_{h} & \text { specimen hot side temperature }(\mathrm{K}) \\ T_{m} & \text { mean specimen temperature }(\mathrm{K}) \\ W B T & \text { warm boundary temperature }(\mathrm{K}) \\ & \\ G r e e k & \text { Symbols } \\ \varepsilon & \text { surface emissivity } \\ \varepsilon^{*} & \text { effective emittance } \\ \sigma & \text { Stefan-Boltzmann constant }\left(\mathrm{W} / \mathrm{m}^{2} \cdot \mathrm{K}^{4}\right)\end{array}$

\section{REFERENCES}

Aegerter, M.A., Leventis, N., Koebel, M.M., 2011, Aerogels Handbook, Springer, New York, NY. https://doi.org/10.1007/978-1-4419-7589-8

ASTM C 177 - 13, 2013, "Standard Test Method for Steady-State Heat Flux Measurements and Thermal Transmission Properties by Means of the Guarded-Hot-Plate Apparatus", American Society for Testing and Materials International, West Conshohocken, Pennsylvania.

ASTM C 1044 - 98, 1998, "Standard Practice for Using a GuardedHot-Plate Apparatus or Thin-Heater Apparatus in the Single-Sided Mode", American Society for Testing and Materials International, West Conshohocken, Pennsylvania.

ASTM C 1774 - 13, 2013, "Standard Guide for Thermal Performance Testing of Cryogenic Insulation Systems", American Society for Testing and Materials International, West Conshohocken, Pennsylvania.
Boedeker Plastics, Inc., "Industrial Laminate Specifications GlassBased Phenolics," www.boedeker.com, accessed 14 Jan. 2016.

Finckenor, M.M., and Dooling, D., 1999, "Multilayer Insulation Material Guidelines," National Aeronautics and Space Administration, Marshall Space Flight Center, AL.

Gilmore, D.E., 2002, Spacecraft Thermal Control Handbook, Vol. 1, 2nd ed., The Aerospace Press, El Segundo, CA.

Irick, K.W., Hengeveld, D.W., 2016, "Single-sided Guarded Hot Plate Method for Comparative Testing of Thermal Radiation Barriers in Vacuum," 46 ${ }^{\text {th }}$ AIAA Thermophysics Conference, AIAA Aviation, (AIAA 2016-3699), American Institute of Aeronautics and Astronautics, Washington, DC.

http://dx.doi.org/10.2514/6.2016-3699.

National Institute of Standards and Technology, Material Measurement Laboratory, "Material Properties: G-10 CR (Fiberglass Epoxy)," www.cryogenics.nist.gov, accessed 19 Oct. 2016.

Shang, S., and Zhao, D., 2012, Aerospace Materials Handbook, CRC Press, Boca Raton, FL.

\section{APPENDIX A: SPECIMEN DIMENSIONS}

Tables 8 through 12 show the dimensions of each specimen tested. Here, $w$ is the width of the specimen (specimens are squares), $t$ is the specimen thickness, $m$ is the mass of the specimen, and $h$ is the approximate gap distance between the warm boundary heat transfer surface and the hot side surface of the specimen. The thickness measurement of each specimen was made prior to the mounting of specimen temperature sensors and prior to installation of the specimen into the test apparatus. Eight measurements were made using calipers around the perimeter and near the edges of a given specimen.

Table 8 MLI dimensions

\begin{tabular}{|c|c|c|c|}
\hline$S N$ & 5L-MLI-001 & 8L-MLI-001 & 10-MLI-001 \\
\hline$w(\mathrm{~m})$ & 0.3112 & 0.3163 & 0.3096 \\
\hline$t(\mathrm{~m})$ & 0.00421 & 0.00308 & 0.00528 \\
\hline$m(\mathrm{~kg})$ & 0.01704 & 0.02181 & 0.02983 \\
\hline$h(\mathrm{~m})$ & 0.01588 & 0.01588 & 0.01588 \\
\hline
\end{tabular}

Table 9 Hand-taped dimensions

\begin{tabular}{|c|c|c|c|}
\hline$S N$ & HT-G2_-001 & HT-G2_-002 & HT-G2_-003 \\
\hline$w(\mathrm{~m})$ & 0.3069 & 0.3076 & 0.3068 \\
\hline$t(\mathrm{~m})$ & 0.00895 & 0.00970 & 0.00953 \\
\hline$m(\mathrm{~kg})$ & 0.04899 & 0.05450 & 0.04898 \\
\hline$h(\mathrm{~m})$ & 0.01905 & 0.01905 & 0.01905 \\
\hline
\end{tabular}

Table 10 Ultrasonically-sealed dimensions

\begin{tabular}{|c|c|c|c|}
\hline$S N$ & US-G2_-001 & US-G2_-002 & US-G2_-003 \\
\hline$w(\mathrm{~m})$ & 0.3239 & 0.3242 & 0.3239 \\
\hline$t(\mathrm{~m})$ & 0.00707 & 0.00696 & 0.00779 \\
\hline$m(\mathrm{~kg})$ & 0.04658 & 0.04545 & 0.05415 \\
\hline$h(\mathrm{~m})$ & 0.01905 & 0.01905 & 0.01905 \\
\hline
\end{tabular}

Table 11 Multi-layer Aerogel Insulation White dimensions

\begin{tabular}{|c|c|c|c|}
\hline$S N$ & MA- $-\mathrm{W}-001$ & MA- $\_\mathrm{W}-002$ & MA- $-\mathrm{W}-003$ \\
\hline$w(\mathrm{~m})$ & 0.3242 & 0.3239 & 0.3242 \\
\hline$t(\mathrm{~m})$ & 0.00556 & 0.00487 & 0.00520 \\
\hline$m(\mathrm{~kg})$ & 0.05547 & 0.05608 & 0.05577 \\
\hline$h(\mathrm{~m})$ & 0.01588 & 0.01588 & 0.01588 \\
\hline
\end{tabular}


Table 12 Multi-layer Aerogel Insulation Black dimensions

\begin{tabular}{|c|c|c|c|}
\hline$S N$ & MA-_B-001 & MA-_B-002 & MA-_B-003 \\
\hline$w(\mathrm{~m})$ & 0.3242 & 0.3246 & 0.3239 \\
\hline$t(\mathrm{~m})$ & 0.00606 & 0.00699 & 0.00667 \\
\hline$m(\mathrm{~kg})$ & 0.05820 & 0.05558 & 0.05862 \\
\hline$h(\mathrm{~m})$ & 0.01588 & 0.01588 & 0.01588 \\
\hline
\end{tabular}

$$
\begin{aligned}
& W B T=W B T_{1} \\
& C B T=\left(C B T_{1}+C B T_{2}+C B T_{3}\right) / 3 \\
& Q_{G H P}=V \cdot I
\end{aligned}
$$

\section{APPENDIX B: UNCERTAINTY}

Referring to Eq. (1), parameter values $W B T, C B T, Q_{G H P}$, and $T_{m}$ are calculated from multiple measurements, including one $W B T$ temperature measurement, $W B T_{1}$, three $C B T$ measurements, $C B T_{1}$, $C B T_{2}$, and $C B T_{3}$, a voltage measurement, $V$, a current measurement, $I$, and three specimen hot side temperature measurements, $S P T_{1}, S P T_{2}$, and $S P T_{3}$. The parameters are calculated using the following Eqs. (5) through (8).

Uncertainty on temperature measurements ranges from $\pm 1.32 \mathrm{~K}$ to $\pm 1.65 \mathrm{~K}$. Voltage measurement uncertainty ranges from $\pm 0.30 \%$ to $\pm 1.10 \%$, and current measurement uncertainty ranges from $\pm 0.04 \%$ to $\pm 4.05 \%$ 